\title{
Building a Talent Management System
}

\author{
Natalya Rinatovna Balynskaya \\ Oksana Nikolaevna Sinitsina
}

Nina Vladimirovna Kuznetsova

Olga Leonidovna Nazarova

Nosov Magnitogorsk State Technical University, Correspondence: Natalya Rinatovna Balynskaya, Nosov Magnitogorsk State Technical University, Chelyabinsk Region, Magnitogorsk, Russia; E-mail: balynskaya@list.ru

\section{Doi:10.5901/mjss.2015.v6n5s4p279}

\section{Abstract}

This article deals with the topical issues of building a talent management system in a modern organization and analyzes the singularities of the formation of a talent management system. It is concluded that building and using the human resource capacity of employees in a modern organization in the market conditions is a set of processes, which are challenging by the organization and management approach and are affected by numerous factors. The human resource capacity is built and used based on a number of specific principles and requires studying in order to improve the organization of labor and production in the conditions of acute competition between enterprises. The article discusses the "human resource management," "human resource capacity," "talent management system" concepts. The principles of a talent management system formation in an organization, which take into account the connectivity of employees and the organization's interests, are suggested. The tactical and strategic lines of development of the talent management system of an organization were developed. The tactical line assumes the implementation of the current human resources-related functions of the management. Strategically, it is focused on the general achievement of the organization's goals. The article reveals the essence of the rational use of the organization's staff, which consists in full implementation of the capacity of each employee of the organization, in making the labor more creative and meaningful, in the improvement of the professional qualification of the employees, taking into account its comprehensive motivation and appropriate assessment of the contribution of each employee to the operating results. It also proves the necessity of creating such a system, which would optimally combine the subsystem of formation and the subsystem of utilization and development of the human resource capacity.

Keywords: human resources, human resource management, human resource capacity, talent management system

\section{Introduction}

One of the priorities of the country's development is the modernization of the economy, which would provide the growth of labor productivity, the removal of obsolete equipment from the fixed assets, the increasing usage of advanced technologies, and more. However, no modernization is possible without qualified personnel and specialists who would solve these problems.

Human resources management is one of the most important functions of any organization, and this aspect becomes of particular importance in the modern circumstances of the market economy. Staff motivation, labor productivity, and, consequently, the profits of the enterprise depend on how the management conducts the personnel policy. The transition to modern, innovative technologies in the field of personnel management is impossible without the effective use of the potential that every employee has. Today, insufficient attention is paid to the analysis of the personnel policy and efficient use of the talent pool of organizations.

To operate effectively, an organization needs to invest not only in the production and management, but also in human resources. Economic difficulties force us to revise the theoretical approaches to the utilization of the talent pool of organizations. Therefore, one of the main tasks at the current stage is to find ways to improve the talent management systems of organizations.

In this regard, it seems reasonable to study comprehensively the human resource capacity, the problems of its development, the assessment of the current state, and the development of proposals to elaborate a talent management system. 
Experience in talent management at organizations is considered in the works of foreign scientists, such as $\mathrm{G}$. Ivantsevich, M. H. Mescon, M. Albert, F. Khedouri, R. Mahr, H. Schmidt, etc. The basic ideas of the theory of human capital were set out in the writings of G. Becker, J. Mincer, T. Schultz, etc. The issues of talent management were approached by Russian scientists, such as V. V. Adamchuck, V. G. Afanasyev, V. R. Vesnin, A. P. Volgin, L. S. Degtyar, A. Ya. Kibanov, I. S. Maslova, Yu. G. Odegov, V. T. Pulyaev, L. S. Chizhov, etc. They investigated the theoretical and applied problems of personnel management optimization, formation of a personnel management system in industrial and other organizations.

\section{Literature Review}

Most Russian and foreign authors consider the concepts "human resource capacity" and "human resources management" only in connection with each other, since only the skillful management can ensure rational use of human resources and effective performance of an organization in a highly competitive market (Travin, 2009).

Human resources management is a multifaceted and complex process, which has its own specific features and regularities. Human resources management is understood as a purposeful activity of the enterprise management, managers and specialists of human resources departments, which involves the development of the concept and strategy of human resources policy, the principles and methods of human resource management (Zhukov, 2005). In practice, it consists in the formation of a human resources management system, personnel management planning, development of human resources management plans, marketing of the enterprise personnel, and defining the human resource capacity of the enterprise.

However, human resources are, above all, the people who have a set of individually typical qualities and features, amongst which the social and psychological ones play a crucial role. Therefore, the subject of human resource management are the relations of employees in terms of the most complete and effective utilization of their capacity in terms of the enterprise's operation. The main objective of human resource management in modern conditions is to combine effective training of the personnel, qualification upgrade, and labor motivation to develop the employees' skills and encourage them to work with high quality.

One of the interpretations of the "capacity" concept is its consideration as a source of capabilities and means that can be activated and used to solve a problem or achieve a particular purpose of the organization.

Human capital is the knowledge, skills, and motivations that anyone has. Investments in human capital are education, accumulation of work experience, health security, geographical mobility, and information retrieval (Isachenko, 2013).

The organization's human resource capacity in the broadest sense is the knowledge and skills of employees, which can be used by the enterprise to gain profit and achieve a social effect. The human resource capacity can be seen in a more narrow sense-as a temporary free or reserve jobs that could potentially be occupied by specialists as a result of their development and training. Talent management should help order the personnel, maintain its quality, improve and develop it.

Human resource capacity of an organization is a generalized (quantitative and qualitative) characteristic of the personnel as one of the types of resources, related to the implementation of its functions and the achievement of longterm development goals of the organization; the existing and potential capacity of employees, as an integrated system, which are and can be used at a certain moment.

In turn, the difference between "personnel" and "human resource capacity" was emphasized by N. P. Belyatsky, S. E. Veselko, P. Reusch, A. Y. Kibanov and others. They believed that while "personnel" is the total of employees of certain professions and specialties, levels of training and education, the human resource capacity includes not only the personnel, but also a certain range of opportunities of this group of employees in the implementation of targeted actions arising from the problems of functioning and development of the system (Belyatsky, 2002; Kibanov, 2010). The organization's human resource capacity depends on the capacity of the personnel of the organization, but it is not just their sum. It has the property of integrity, fundamentally different from the properties inherent to the capacity of each employee individually.

The view of T. V. Berglezova who explored the features of the human resource capacity in the industry is close to this concept. In her view, the main difference between these two closely related concepts is that personnel, in particular, is full-time employees performing specific duties. And the human resource capacity significantly exceeds the number of people employed in the industry. The human resource capacity includes all working and not working people who can perform certain functions according to their education, experience, and qualifications, but for various reasons are not engaged in the system or engaged not in accordance with their level of education and qualification (Berglezova, 2005). 
Thus, though the category of "human resources" gives the idea of the professional and qualification features of employees, it essentially discloses only the static side of the properties and qualities inherent in this category. It does not reflect the diversity of dynamic attributes, such as mobility of personnel, ability to solve certain professional tasks. The category "human resource capacity" is more acceptable for these purposes.

V. A. Dyatlov and V. T. Pikhalo defined human resource capacity as "a set of abilities of all people who are engaged in the organization and fulfill certain tasks. Human resource capacity is contained in those functions that the employee performs as a professional and by virtue of his skills, knowledge, and experience can ensure the effective operation of production" (Dyatlov, 2010).

Thus, we can state that human resource capacity is a general characteristic of abilities and capabilities of the organization's employees who have certain qualifications, have passed preliminary vocational training, have special knowledge, skills, and experience in a certain field of activity, and can effectively carry out their functions and provide certain economic performance in line with current and future goals of the organization (Maslov, 2009).

The parameters or characteristics of the human resource capacity can be classified as follows (Kuzmina, 2004):

- The psycho-physiological capacity (the abilities and inclinations of a person, his/her health, performance, endurance, etc.); $T$

- The qualification capacity (the volume, depth, and diversity of knowledge and expertise, labor skills that determine the ability of the employee to certain work of certain complexity);

- The personality potential (the level of civic consciousness and social maturity, the degree of employee's knowledge of labor attitude standards, value references, interests, needs, and demands in the labor field, based on the hierarchy of needs).

Personal characteristics of an employee form a separate group of internal factors of the formation of a talent management system. The most important of these characteristics usually are:

- Motivation to work. An important function of human resource management is the attraction and development of such personnel who would fully meet the requirements of the organization. For this purpose, a system of external influences on the behavior of workers should be developed, which would allow to making full use of their potential. Comprehensive application of a variety of economic, social, and socio-psychological stimuli, their short impact on different groups of employees allow achieving their positive attitude towards the work and high quantitative and qualitative labor performance. A system of payment and incentives for the end product can meet best the interests of an enterprise and employees.

- Proper planning and management of human resources in the development of organizations significantly increases the opportunities, motivation, and overall effectiveness of personnel development (Vijayaragavan \& Singh, 1997). In order to have a high team spirit, it is important that people receive adequate compensation and recognition for their work.

- Professional qualification level. Basic professional education, as well as organization and promotion of continuous professional training of employees are the determining factors in the formation of a talent management system of an organization. All conditions for continuous professional training of employees and the actual use of the results of this training must be provided (improvement of the techniques and methods of work, productivity growth, improvement of the quality of work performance, improvement of the employee's competence, and so on).

- The problems that arise in the development of the capacity are important sources of knowledge and are treated as such (Ubels et al., 2010). The knowledge of employees is a key factor determining the value of the organization. Therefore, enterprises should be able to define, manage, and measure those (Malik \& Malik, 2008). It is necessary for organizations to assess the results of not only basic training of employees, but also the continuous professional training (forms, duration, relevance, and effectiveness from the standpoint of the requirements of the enterprise).

- Experience. In the practice of rational use of the human resource capacity of employees, the professionalism and skills of employees are taken into account, which are largely determined by the experience (Posherstnik, 2008). The manager should know about the personal experience, which brings a person to awareness and understanding of himself, and how it affects other people (Reilly, 1998).

- Labor performance. The psychophysiological possibilities of employees have limitations. However, in practice, if the labor is approached scientifically and they are motivated, they can be developed and used at the breaking point corresponding to the necessary evidence-based labor costs in particular organizational and technical conditions (Kibanov, 2010).

- Personal characteristics. As the personal characteristics of employees may be very diverse, i.e., they are 
specific for each case of building and using the human resource capacity of the organization's personnel, the system of human resources management should be focused on the following major tasks of innovative development of both a separate enterprise and the society as a whole.

Firstly, ensuring compliance of the quantitative and qualitative characteristics of the staff to the goals of the organization (Shapiro, 2007).

Secondly, consolidation of employees not only at the organizational level, but also at the level of common goals, values, and traditions, which means the formation of a loyal and highly motivated team of professionals united by common goals and corporate culture (Kuzmina, 2004).

At the same time, different authors associated a different set of functions with the process of talent management. S.A. Shapiro represented talent management through the functions of planning and evaluation of staffing needs, the search and selection of staff, and staff adaptation (Shapiro, 2007). N. V. Kuzmin represented talent management through the systems of competence management, vocational training, and business career management (Kuzmina, 2004). Y. N. Arsenyev suggested business career management as the key function of talent management (Arsenyev, 2012).

Domestic and foreign scholars believe that human resource capacity can be considered from two perspectives: from the perspective of its development and from the perspective of its exploitation. In practice, the processes of building and using the human resource capacity are closely interrelated (Dyatlov, Kibanov, \& Pikhalo, 1998).

Staff development can be seen as a special area of human resource management, which includes planned individual training, education, career development, and qualification upgrade (Treven, 2001). Successful changes in the organization are a gradual process, so it is better to set realistic goals and try to move from one stage to another, focus on what is most realistic and achievable given the available human and financial resources.

We agree with the point of view of T. V. Berglezova that the efficiency of an enterprise directly depends on how talent management that affects the success of each employee is organized. In order to manage the human resource capacity effectively, an organization must (Berglezova, 2005):

- Eestablish science-based labor standards and revise them as the organizational and technical conditions of production improve;

- Carry out certification and streamlining of jobs, define the required number of them, and abolish unnecessary jobs;

- Set the forms of the employees' labor organization and work categories, assign categories to workers, organize introducing advanced techniques and methods of labor;

- Set the working practices, introduce flexible schedules, allow part-time work, and organize home work.

Planning, organization, and control over the functioning of the talent management system become the most important task of talent management. This problem can be solved via a set of efforts, such as: 1) Clear allocation of duties; 2) Professional and career advancement of employees through the ranks, taking into account the results of their evaluation and individual characteristics; 3) Regular training and qualification upgrade; 4) Creation of other conditions that motivate employees to work more effectively; 5) Career planning.

\section{Methodology}

\subsection{Factors of the Talent Management System Formation}

A talent management system is a set of mutually influencing individual functional subsystems implementing coordinated activities, the aim of which is to ensure full and timely formation, development, and use of the capacity of each employee (Figure 1).

The main objective of a talent management system is to provide the functional and industrial subsystems of an organization with the required employees in the required quantity and of the required qualification. This goal is achieved through the effective human resources management in the field of recruitment, evaluation, labor adaptation, incentives, motivation, training, certification, labor and workplace organization, the use of personnel, career planning, succession management, management of innovations in the personnel management, safety and release of the personnel. 


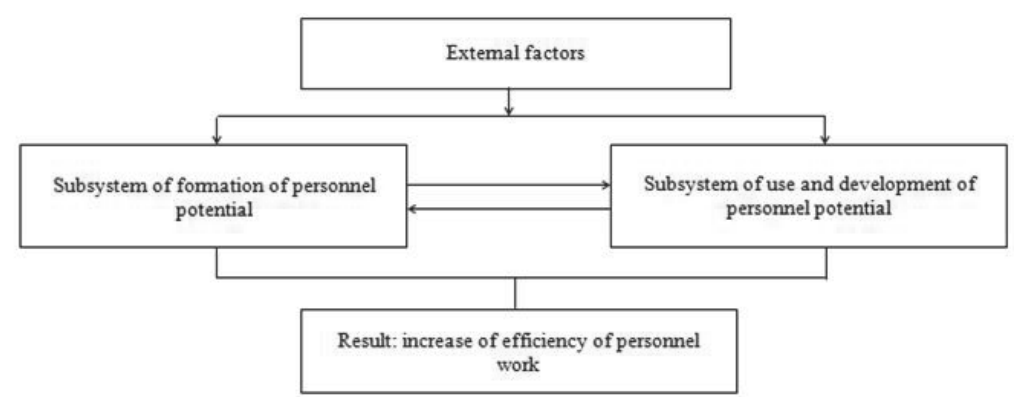

Figure 1. Talent management system

The main goal determines the sub-goals and principles of the talent management system, which reflect the objective tendencies, social and economic laws, and recommendations of management theory.

The system approach is based on the multi-level hierarchy of structural organization of any object. It allows revealing the specifics of each of these levels and, at the same time, representing them in unity. The system approach focuses the science and practice on achieving a holistic, synthetic vision of the studied and managed complex objects.

Forming a talent management system, one must consider the impact of the internal and external (in relation to the enterprise) factors on the system. The factors of building and using the human resource capacity of an enterprise in our view are the external and internal conditions of the environment, in which the processes of building and using the human resource capacity are implemented.

External factors are understood as the factors that the enterprise cannot change, but must take into account in the formation and use of its human resources. Internal factors are the conditions that are largely amenable to control impacts on the part of the enterprise. Figure 2.

Generalized classification of factors in the formation of talent management system of an organization is shown in

1) Social and political factors. Governmental support for the unemployed population creates objective prerequisites for building the high quality human resource capacity and its effective (more intensive) use by organizations (Mishurova, 2009).

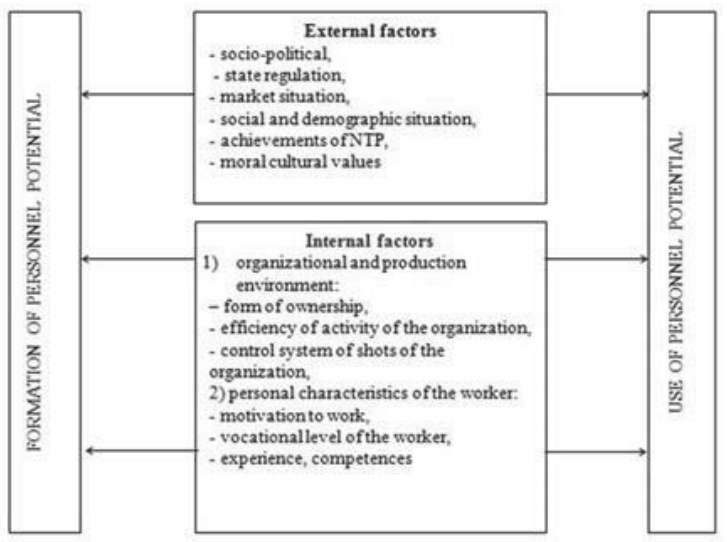

Figure 2. Factors of the formation of a talent management system of an organization

2) Government control. Government control over building the human resource capacity is accomplished currently by three main groups of methods:

- Legislative methods that establish the institutional framework for overall development of any socioeconomic 
process (in dealing with building and using the human resources of an enterprise, one should take into account the issues of labor legislation, its ability to change in the foreseeable future, particularly the legislation on occupational safety and health, employment, etc.);

- Administrative methods, which are used to approve and put into effect any administrative rules and regulations, provisions, instructions, recommendations, etc.;

- Economic methods, by which the government stabilizes the situation on the market (pricing, taxation, adoption of socioeconomic regulations and standards, as well as minimum social guarantees, etc.).

3) The market situation, as a network of peer relations based on the sale of products and services, property relations, balance the interests of the seller and the buyer, the owner and the employee. In modern conditions, the main thing within an organization is its human resources, and beyond the organizationconsumers of its products (services rendered).

4) The socio-demographic situation in the region is characterized by the composition and structure, as well as the shape and intensity of the movement of personnel inside an organization, as well as outside it. For an organization, it becomes very urgent to preserve, develop, and use in the most efficient way the existing staff, and to ensure the influx of young, enthusiastic, and highly qualified "fresh" labor resources from the available ones in the region.

5) Achievements of the progress in science and technology. The implementation of new technology and new equipment, introduction of new products in a highly competitive environment cause constant updating of the theoretical and especially practical knowledge of employees of an organization due to the changes in the scope and content of the functions performed. It is taken into account when hiring new employees or developing systems of incentives and career advancement based on the improvement of professional skills, knowledge, and experience of the organization's personnel.

6) State of the education system. The availability of public and private educational institutions, the content of vocational education programs, advantages and disadvantages of professional training, cost of education, career models, regulations on staff training, skills development plans, content of employment contracts, models of jobs (positions), acceptability of reception conditions and learning in colleges and universities influence on the decision of the organization's top management with regard to hiring new employees who already meet all the requirements of the employees or investing in the development of human resources capacity of the current permanent staff (McNaughton, 2004).

7) Moral and cultural factors. The shared values, social standards, and behavior patterns generated by the society, a group of people, regulate the actions of employees and make them to behave in a certain way without any visible coercion.

8) Prestige of the industry. In some sectors of the national economy, there are virtually no problems associated with building the human resource capacity due to a very stable staff of employees of these industries because of favorable labor conditions in these industries (Kibanov, 2010).

When building a talent management system at the level of an organization, it is necessary to take into account the state of the production organization environment. Production organization environment should take into account the impact of the following factors:

1) Ownership. This factor determines the priority of the interests of owners of enterprises and employees in the process of organization and management of labor and production, and in building and using the human resource capacity. In modern conditions, the processes of building and using the human resource capacity in the private sector of the economy are to meet more stringent requirements for the professional, labor, and personal characteristics of candidates at hiring. The labor conditions, as well as the nature of the work of these employees also indicate a more intensive use of the personnel of private enterprises.

2) The operating efficiency of an enterprise. The economic and financial position of an organization largely determines the success of managing the processes of building and using the human resource capacity, because the procedures such as recruitment, selection of personnel, vocational guidance and adaptation, training of personnel, and others require significant expenditures in the current circumstances. However, these investments pay off very soon as a result of admission to work and highly effective performance of skilled employees.

3) Organizational and technical factors. Their effect manifests itself in the implementation of such forms and methods of production organization as mass production and specialization in the production of certain products, continuity of production processes, use of science-based standards of labor costs; changes in the scope and content of labor functions performed, the productivity of labor; specific characteristics of the 
equipment used, etc.

4) The human resources management system of an enterprise. The structure of the human resources department is largely determined by the nature and size of the organization and the peculiar features of products. At small and medium-sized enterprises, many functions of human resources management are performed mostly by line managers, and at large ones, independent business units are formed.

It is necessary to use an effective system of talent management to turn the consciousness of each employee towards consumers, and not to the supervisor; to the operating results of the organization, not to wastefulness; to a proactive highly qualified productive worker, not to a faceless performer. Any changes in the market of goods or workforce should be reflected in the processes of building the human resources of an organization and their employment.

\subsection{The Principles of Building a Talent Management System}

The purpose of a personnel management division consists just in the evaluation of the current external and internal situation in the organization's activity, based on which the sufficiency of highly skilled relevant personnel in the required number is identified; as well as the need for additional staff, which can be satisfied both from internal and external sources of employment.

Talent management within the system should be based on the following principles:

1) Effectiveness of selection, deployment, and use of the personnel;

2) Fair stimulation of labor and staff qualification upgrade;

3) Possibility of real career advancement in accordance with the performance, skills, abilities, personal interest, and the organization's needs;

4) Regularity of the human resource capacity assessment and forecasting of the trends among the enterprise's employees and on the regional labor market.

At the same time, in our opinion, the system of human resources management, as an open and complex system, is based on the following principles:

1) The principle of non-additivity (it is based on the fact that a large talent management system is not a mere sum of its constituent systems;

2) The principle of emergence (determines the level of coincidence of the targeted functions of the talent management system and its subsystems);

3) The principle of adaptability (it is based on the necessity of the talent management system to adapt to the changing internal and external conditions to maintain its functional stability);

4) The principle of alternativeness (it is based on the dependence of the decisions made by managers or specialists of the HR department on the parameters and conditions of specific situations that arise in the process of building and using the human resource capacity of employees);

5) The principle of integrity (it means that the talent management system exists as an organizational and functional integrity, in which each subsystem performs certain functions);

6) The feedback principle (it consists in the fact that the information on the key characteristics of the staff comes and is used in the organization for the talent management process);

7) The principle of multiplicity (it is based on the fact that positive and negative effects in the system have the properties of multiplication instead of addition. They should be taken into account to avoid disorganizing the talent management system);

8) The principle of compatibility (it is based on the compatibility of each of the subsystems of talent management with not only the large system - the system of personnel management—but with all its components).

All the principles are interrelated, and only the integrity of their applications will ensure the success of the system of senior pupils' knowledge update in the course of economic education. We base on the assumption that principles constantly evolve and are improved and specified. The system of principles is always open to additions and changes based on new experience, its analysis, comprehension, and synthesis. The proposed principles of organization's talent management are remarkable as they account for the possibility of connecting the interests of employees and of the organization.

\subsection{Elements of the Talent Management System}

A talent management system is a holistic system of interrelated elements, a set of mutually influencing individual functional subsystems (Figure 3). 
The activity of an HR department at building a talent management system should be based on the monitoring of the enterprise's staff. Staff monitoring is understood as the permanent operational survey of the personnel state and movement (both in quantitative and qualitative terms). This is a key subsystem of an organization's talent management system that determines the focus of all other subsystems.

Many modern organizations are extremely irregular or one-sided in the assessment of the production program staffing, planning and forecasting of the personnel requirement in accordance with planning in other business lines of the enterprise. Traditionally, domestic enterprises have been planning and forecasting the total quantitative personnel requirement, the structure of personnel for each category of employees needed by the enterprise in the current or future period to perform scheduled tasks (responsibilities) with the best efficiency and quality.

In recent years, the systematic approach to human resources management becomes particularly relevant. During the formation of this function, it is necessary to analyze thoroughly the situation on the external and internal labor market, allocate various categories of personnel in order to implement different human resource management approaches to hiring, labor incentives, qualification upgrade, career advancement, and so on. The hiring subsystem must examine the compliance of employees with the job position by gender, age, professional knowledge, marital status, health, temperament, etc. All of these quality characteristics allow avoiding overstating or understating the requirements for the job, prevent occupational injuries, occupational diseases, and early disability at the enterprise, which is necessary to reduce additional personnel-related costs.

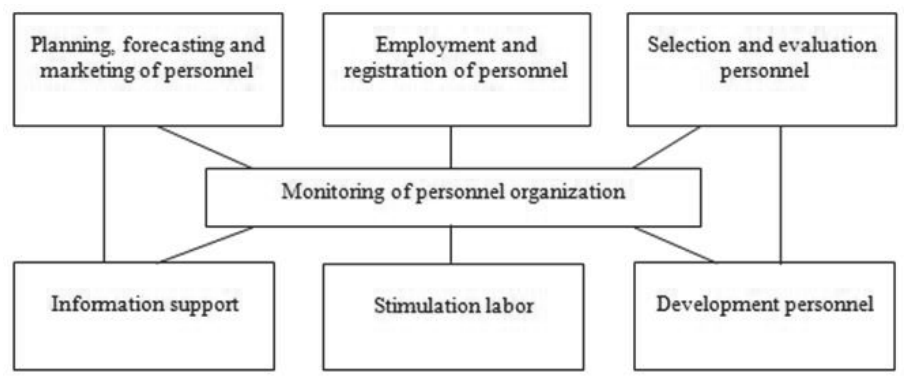

Figure 3. Elements of a talent management system

The hiring subsystem enables staffing an organization in qualitative and quantitative terms. The organization should maximize the use of the existing human resources before seeking external sources of employment.

This subsystem is closely linked to the subsystem of selection and evaluation of personnel. Many scholars have pointed out the importance of personnel evaluation, evaluation of candidates for positions, evaluation of employees after the end of the probation term, periodic, regularly repeated current evaluation in order to determine the qualification of the employee for the occupied position, evaluation of candidates in various forms of training and qualification upgrade, and so on.

Many organizations have no special regulatory framework for the selection and evaluation of personnel; no work on drawing up job descriptions has been organized; the staff schedule is being developed as well as changes thereto based on the current organizational structure; no harmonization of job descriptions for different departments is being performed. This leads to dissociation of the functions of building and using their human resource capacity.

In the selection of staff, it is imperative to introduce special questionnaires that allow, on the one hand, to simplify the selection procedure, and on the other-to prepare information on the applicants reserve for a particular job.

The subsystem of human resources development is represented with a wide variety of functions. The main functions of the management of building and using the human resource capacity of an enterprise are:

1) Vocational training;

2) Succession management;

3) Planning and control of business career;

4) Professional and socio-psychological adaptation of new employees.

The main problems in this area are:

1) Poor understanding by many organizations of the fact that the investments in training their staff are the investments in fixed assets and the future development of the organization, allowing to use more efficiently the 
latest technology and the personnel capacity;

2) Identification, appropriate incentives, and rapid advancement of young professionals;

3) Organization and stimulation of personnel advancement. It is very important to develop approaches to the advancement of each functional and qualification group of employees based on the economic feasibility of such advancement for the enterprise and financial interest of the employee and on the introduction of age, educational, professional, and time constraints;

4) The absence of a clear understanding of the efforts to accelerate the employment adaptation of new employees, because there is no complete information about the new employees and the organization on the stage of "familiarization" with each other, and often there is no functional organization of adaptation in the human resources management system;

5) In modern organizations, employers are not always interested to make the employees to believe in the prospects for their professional advancement with the prospects of the organization development.

The subsystem of labor stimulation is based on the rich experience of material (monetary and non-monetary, primary and secondary), moral, labor, and other types of staff incentives.

In building a talent management system in an organization, it is important to consider the motives of employment or election to office, the tangible and intangible benefits that are expected by the new employee at the new job. And when the human resource capacity is used with skillful organization of labor, one can always achieve the necessary quantitative and qualitative results of labor and production.

The last subsystem determines the performance and interaction of all of the above subsystems. Information support implies providing all subsystems with complete, accurate, and timely information on all issues related to the building and using the human resource capacity of the organization, which requires implementing automated accounting and analysis of the organization's personnel and development of an appropriate regulatory framework.

The practice of building a talent management system has two main lines: tactical and strategic. The tactical line assumes the implementation of the current human resources-related functions of the HR department. The strategic direction is focused on the development of the human resources policy of the enterprise (a system of ideas, concepts, particular efforts on human resources management, as well as its methods). For a modern organization, it is very important to coordinate and integrate the strategic planning and forecasting in the field of human resource management with the strategic development of other business lines of the organization.

Thus, a fundamental factor in the economic growth of an enterprise is an adaptive, flexible human resources policy and a clear talent management system. The building and using the human resource capacity of employees in a modern organization in the market conditions is a set of processes, which are challenging by the organization and management approach and are affected by numerous factors. The building and using the human resource capacity is based on a number of specific principles and requires studying and systematically approaching it production in the conditions of acute competition between enterprises.

\section{Conclusion}

The article has considered the talent management as a system that includes the human resource capacity building, its development, and effective use. The basic factors that influence the formation of this system have been described. It has been concluded that the human resource capacity is an aggregate of abilities and capabilities of employees who have passed preliminary vocational training, and who have proper qualification, knowledge, skills, and experience in a particular field of activity. The "human resource management", "human resource capacity", "talent management system" concepts have been considered.

As the analysis has shown, a formed talent management system determines the success of each employee's activity and the efficiency of the enterprise as a whole. For its implementation and functioning, an organization should:

1) Set standards of work and revise them along with the introduction of new technologies;

2) Provide periodic certification and streamlining of jobs;

3) Improve the employee's labor organization; implement innovative methods of work;

4) Establish a flexible mode of work;

5) Organize timely training and qualification upgrade for the employees;

6) Develop individual career advancement maps;

7) Study the motivating factors and implement incentive systems;

8) Study the causes of downtime and constantly carry out preventive measures;

9) Develop effective methods for conflict and stress management. 
Thus, the answer to the questions "how to develop?" and "how to use the labor potential?" should not only provide for the implementation of innovative experience of advanced companies, but also ensure the creative development and formation of personal orientations and priorities of each employee.

The effectiveness of the proposed talent management system can be confirmed by the increased labor productivity in specific production conditions, decreased downtime and number of conflicts, increased labor motivation and commitment of employees to their organization.

\section{References}

Arsenyev, Y. N., Davydova, T. Y., \& Shelobaev, S. I. (2012). Human resource management. Management models. Study guide for students (p. 288). Moscow: UNITY-DANA.

Belyatsky, N. P., Velesko, S. E., \& Roysh, P. (2002). Human resource management (p. 352). Moscow: Interpresservis.

Berglezova, T. V. (2005). The concept of human resource capacity and its impact on the efficiency of an industrial enterprise. Problems of entrepreneurship in the Russian economy, 8. Retrieved September 23, 2014, from http://www.cfin.ru/bandurin/article/sbrn08/ 07.shtml

Dyatlov, V. A., Kibanov, A. Y., \& Pikhalo, V. T. (1998). Human resource management: Study guide (p. 512). Moscow: PRIOR Publishing House.

Dyatlov, V. A., \& Pikhalo, V. T. (2010). Human resource management: Textbook. A manual for students of economic universities and faculties. Moscow: PRIOR.

Kibanov, A. Y. (Ed.). (2010). Human resource management in an organization: Textbook (4th ed., p. 695). Moscow: INFRA-M.

Isachenko, I. I., Elizarova, O. I., Condrus, E. A., \& Mashinskaya, I. S. (2013). Human resources management: Textbook (p. 206). MGUP, Moscow: Moscow State University of Printing Arts.

Kuzmina, N. V. (2004). Labor potential management system in integrated corporate structures (Thesis of PhD in Economy). Moscow.

Malik, K. P., \& Malik, S. (2008). Value Creation Role of Knowledge Management: A Developing Country Perspective. The Electronic Journal of Knowledge Management, 6(1), 41-48. Retrieved from www.ejkm.com

Maslov, E. V. (2009). In P. V. Shemetov (Ed.), Human resource management in an organization: Textbook. Moscow: INFRA-M.

McNaughton, D., Karison, D. J., \& Townsend, D. C. (2004). Human resources of modern organizations (p. 549). Moscow: UNITY-DANA.

Popov, L. A. (1999). Analysis and modeling of labor performance indicators (p. 208). Moscow: Finansy i Statistika.

Posherstnik, N. V., \& Meyksin, M. S. (2008). Human resources of an enterprise (p. 296). St. Petersburg: "Publishing House Gerda."

Reilly, A. J. (1998). Three approaches to organizational learning (Vol. 16, 2nd ed.). The Pfeiffer Library.

Shapiro, S. A. (2007). Fundamentals of personnel management in modern organizations: A unique approach that provides efficient operation of the company (p. 248). Moscow: GrossMedia.

Smirnov, B. M. (2011). Staffing innovations in personnel management system (p. 267). Moscow: Varyag.

Smirnov, E. A. (1998). Fundamentals of the theory of organization (p. 340). Moscow: KNORUS.

Mishurova, I. V. (Ed.). (2009). Technology of human resources management: Training and practical guide (p. 274). Moscow: ICC "Mart".

Travin, V.V., \& Dyatlov, V. A. (2009). Basic concepts of human resource management (p. 170). Moscow: INFRA-M.

Treven, S. (2001). Human resource management in international organizations. Management, 6(1-2), 177-189.

Ubels, J., Naa-Aku, A. B., \& Fowler, A. (2010). Capacity development in practice (p. 361). Washington, DC.

Vijayaragavan, K., \& Singh, Y. P. (1997). Managing human resources within extension (Chapter 14). Retrieved from http://www.fao.org/ docrep/ w5830e/w5830e0g.htm

Zhukov, E. F. (2005). Personnel management of the enterprise (p. 288). Moscow: Publishing Association "UNITY." 